Przegląd Badań Edukacyjnych Educational Studies Review

ISSN 1895-4308

nr $30(1 / 2020)$, s. 129-156

ORYGINALNE ARTYKUŁY BADAWCZE

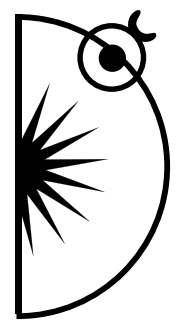

Magdalena Zadworna

ORCID: http://orcid.org/0000-0002-0585-019X

University of Lodz, Poland; e-mail: magdalena.zadworna@uni.lodz.pl

Paulina Michalska

ORCID: http://orcid.org/0000-0003-2179-0307

University of Lodz, Poland; e-mail: paulina.michalska@uni.lodz.pl

Magdalena Kobylarczyk

ORCID: http://orcid.org/0000-0002-7069-316X

University of Lodz, Poland; e-mail: magdalena.kobylarczyk@uni.lodz.pl

\title{
Stress and Coping Strategies Among Participants of Stress Management Interventions at the Science, Technology and Art Festival
}

http://dx.doi.org/10.12775/PBE.2020.007

\begin{abstract}
Introduction: The aim of the study was to measure the level of perceived stress and coping strategies among attendants of the Science, Technology and Art Festival in Lodz in Poland, as well as to identify relationships between these two variables and demographic factors. Method: The research includes the data from 298 volunteers aged 16 to 79 years $(\mathrm{M}=32.09$; SD =14.22). The Perceived Stress Scale was used to assess the level of stress, and Brief - COPE to evaluate coping strategies. Results: Fifty-one percent of participants revealed a high level of perceived stress, with women and younger people tending to be more stressed. Five coping strategies (denial, venting, substance use, behavioral disengagement, self-blame) were positively correlated with perceived stress. Negative relationships were observed between the level of stress and the following coping strategies: active coping, planning, positive reframing, acceptance and sense of humor. The strategy of self-blame turned out to be the strongest predictor of perceived stress. Conclusion: Building self-awareness about the individual level
\end{abstract}


of stress and coping is an important element of promoting psychological well-being. The results of this pilot study may improve stress management interventions in the future.

Keywords: coping strategies, perceived stress, stress management interventions.

\section{Introduction}

Evidence-based knowledge about stress is a key element of health promotion, psychoeducation and stress management interventions. The most widely-accepted view in psychology is that stress is brought on by a relationship with the environment that is perceived as demanding, as beyond the ability of the subject to cope, or as one that threatens the well-being of the subject. This model entails the evaluation of potential harm, threat and challenges, thus facilitating the process of coping with stressful events (Folkman \& Lazarus, 1980; Lazarus \& Folkman, 1984). Such primary appraisal is associated with a secondary appraisal, which initiates the process of coping, consisting of a series of cognitive and behavioral efforts intended to manage external and internal demands appraised as taxing or exceeding an individual's resources (Lazarus \& Folkman, 1984).

Coping styles differ among individuals, even those faced with a similar stressful situation. These differences may be accounted for by different appraisals of the situation or by preferences for different coping styles. Different coping styles may influence the ability to eliminate or reduce the source of stress and its emotional impact. Coping behaviors and strategies have been traditionally dichotomized into categories, such as problem-focused versus emotion-focused, functional versus dysfunctional or engagement versus disengagement (García et al., 2018). One categorization that appears to effectively distinguish successful coping strategies from unsuccessful ones is that of active versus avoidance coping (Billings \& Moos, 1981). Active coping may include an active cognitive and behavioral component, which results in a positive reappraisal of the situation and reduction in the source of stress. Active coping methods include coping efforts regarded as problem-focused, i.e. those designed to change the human-environment relationship, and others as emotion-focused, i.e. efforts intended to regulate the emotional response to the situation (Folkman \& Lazarus, 1980; Billings \& Moos, 1981). However, recent reviews have concluded that coping dimensions are unstable and depend on the type of stress and sample; therefore, attempting to identify a universal adaptive coping strategy may be an illusory goal (Stowell at al., 2001; Garcia et al., 2018). Park et al. (2004) report that the choice of strategy should be dependent on the controllability of the 
stressor: problem-focused strategies are appropriate if the stressor is controllable, whereas emotion-focused strategies are more suitable for coping with uncontrollable stressors.

Although prevention programs and intervention strategies can be constructed, they require the gathering of an extensive scientific body of knowledge about stress and coping. Stress is colloquially considered to have a negative impact on health by acting as a disease-causing phenomenon responsible for life failures and deterioration of functioning. It has been found that the way of thinking about stress itself acts as an independent and significant variable in determining stress response (Crum at al., 2013). Evidence-based knowledge about the phenomenon of stress should therefore be directly linked to an awareness of individually-perceived stress level, individual coping styles and dispositional coping strategies preferences. Irrational beliefs about the harmfulness of stress lead to the development of regulatory measures aimed at avoiding or reducing it. Instead, stress-optimizing approaches conducted through professional psychoeducation are focused on searching for adaptive coping strategies, not only avoiding stressful events (Crum at al., 2020). it has been shown that even a brief period of psychoeducation and one-time stress management intervention can be beneficial for participants (Van Daele at al., 2012; Burkhart at al., 2018).

Stress management interventions may initially be aimed at increasing the self-awareness needed to introduce healthy coping changes. Although stress management interventions vary according to a target group and site of intervention, those based on a cognitive-behavioral approach typically include the following educational topics: 1) a definition of stress and stressors; 2) good and bad stress; 3) somatic symptoms of stress; 4) psychological symptoms of stress; 5) behavioral symptoms of stress; 6) stress and illness; 7) stress management techniques; 8) improvement of adaptive (positive) coping skills; and 9) reducing maladaptive (negative) coping skills (Reynard at al., 2014; Roohafza et al., 2012).

However, volunteers often participating in these types of activities may differ from the general community, and such willingness to participate may also affect the results of interventions (Mughairbi at al., 2019). To design effective professional prevention programs and interventions, it is necessary to diagnose the stress level and typical dispositional coping styles of the target group. Therefore, the present pilot study examines the levels of perceived stress and coping strategies in a group of Polish participants of the Science, Technology and Art Festival: a nationwide activity promoting psychological and general scientific knowledge. Our findings derived from such an intervention with a target group can help improve similar initiatives in the future. 


\section{Aim of the study}

The aim of the study was to measure the level of perceived stress and coping strategies among attendants of the Science, Technology and Art Festival in Lodz in Poland, as well as to establish the relationship between the two variables and demographic factors. The study addresses the following questions:

1. What levels of stress do attendants of Science Festival in Lodz demonstrate, and which coping strategies do they use?

2. How age and gender differentiate the severity of stress and coping strategies?

3. How is the level of perceived stress related to the choice of coping strategy?

4. Which are the predictors of perceived stress?

\section{Methods}

\section{Procedure and sample}

The participants were drawn from a sample of 320 volunteers taking part in the April 2019 Festival of Science, Technology and Art in Lodz, Poland. The inclusion criteria comprised giving informed consent to participate in a stress management intervention based on measuring the level of stress and coping strategies, and approval for the results to be used for scientific analysis. The respondents were informed about the anonymity and voluntary nature of the research. As 22 respondents did not complete the questionnaires or did not consent to make the data available for analysis, a total of 298 participants were finally included in the study. This group of participants comprised 185 women (61.9\%) and 113 men $(37.8 \%)$ aged from 16 to 79 years $(\mathrm{M}=32.09$; $\mathrm{SD}=14.22)$.

The study was conducted during an annual festival intended to promote the achievements of scientific and artistic communities in Lodz, popularize Science and Art, and integrate the academic and non-academic communities within the city. The festival usually includes lectures, shows, artistic performances and open-air activities, in which participation is free and open to everyone. The event is organized by the Lodz Scientific Society, the universities in Lodz, and a number of scientific and technical organizations.

One of the events proposed by the Institute of Psychology, University of Lodz, was carried out to measure the intensity of stress and examine the coping strategies employed by Lodz residents. The study was conducted by a research 
team comprising two faculty members of the Institute, and 30 trained Psychology students. Interventions took place in a specially prepared location in the festival tent, which was located in the city center. The study lasted two weekend days, from 10 am to $6 \mathrm{pm}$ each day. Each participant approached a designated place and completed the questionnaires provided by the student in appropriate conditions. The students were supervised by the faculty members. The participants volunteered to gain some knowledge about their own stress-related psychological functioning.

The data was collected during direct contact with participants using the Perceived Stress Scale and Brief COPE. Each intervention lasted about 25 minutes. The participants were informed of the aim of the research, instructed how to complete the questionnaires and given appropriate feedback comprising the total questionnaire scores, an interpretation of the result (i.e. the level of stress and dominant coping strategies) and recommendations for more adaptive ways of coping and advice on further consultations.

\section{Measures}

Perceived Stress Scale (PSS-10) was administered to assess the level of perceived stress, as a Polish language adaptation by Juczyński and Ogińska-Bulik (2009) of the original version developed by Cohen, Kamarck and Mermelstein (1983). The scale consists of 10 items regarding subjective feelings related to personal problems over the past month, such as "How often have you felt nervous and tense during the last month?". The respondent assesses each statement on 5-point Likert scale from 0 - never to 4 - very often. The overall result is obtained by summing up the answers from 10 items that give a total perceived stress score out of a total of 40 points.

Brief - COPE, a measure of dispositional coping, i.e. typical responses and feelings in situations of severe stress, was administered as the Polish adaptation by Juczyński and Ogińska-Bulik (2009) of an original version proposed by Carver (1997). The tool consists of 28 items grouped into 14 coping strategies acting as subscales, with two items in each (e.g. "I am taking action to improve this situation"; "I don't want to believe that it really happened"; "I reveal my negative emotions"). Each item is rated by the participant on a 4-point Likert scale from 0 (I almost never do it) to 3 (I almost always do that). The results are calculated by summing up the points obtained from the items of each subscale and dividing the total by two. The results of each subscale range from 0 to 3 . 


\section{Results}

The distributions of the variables were tested for normality using the Kolmogorov-Smirnov test. As they were found to have a normal distribution, parametric tests were used for the following analyses. To determine the differences between means, Student's t-test and the F-test one-way analysis of variance were used. The relationships between the variables were established using Pearson's correlation coefficients. Regression analysis was used to identify any predictors of the severity of stress. Analyses were performed using the SPSS-25 package. Table 1 shows the mean values of the obtained variables.

Table 1. Descriptive statistics for PSS-10 and Brief-Cope

\begin{tabular}{lcccc}
\hline & M & SD & Min & Max \\
\hline The severity of stress & 19.97 & 6.92 & 0 & 36 \\
\hline Active coping & 4.46 & 1.33 & 0 & 6 \\
Planning & 4.53 & 1.32 & 0 & 6 \\
Positive reframing & 3.65 & 1.58 & 0 & 6 \\
Acceptance & 3.82 & 1.37 & 0 & 6 \\
Sense of humour & 2.47 & 1.61 & 0 & 6 \\
Turning to religion & 1.57 & 1.95 & 0 & 6 \\
Seeking of emotional support & 3.43 & 1.70 & 0 & 6 \\
Seeking of instrumental support & 3.39 & 1.75 & 0 & 6 \\
Self-distraction & 3.47 & 1.48 & 0 & 6 \\
Denial & 1.33 & 1.43 & 0 & 6 \\
Venting & 3.18 & 1.47 & 0 & 6 \\
Substance use & 1.19 & 1.56 & 0 & 6 \\
Behavioral disengagement & 1.60 & 1.43 & 0 & 6 \\
Self-blame & 3.07 & 1.77 & 0 & 6 \\
\hline
\end{tabular}

Source: Authors' research.

The mean score awarded to severity of stress in the study group was 19.95, which corresponds to 7 sten (high result). A statistically significant difference was observed between men and women with regard to mean PSS-10 score, with women $(\mathrm{M}=21.31 ; \mathrm{SD}=6.67)$ presenting a higher level of perceived stress then men $(M=17.72 ; S D=6.78 ; t=-4.49 ; \mathrm{p}<0.0001)$. 
The findings indicate that 50 of the respondents (16.8\%) reported feeling a low level of stress, with one of the respondents not noticing any symptoms of stress in the previous month. In addition, 96 people $(32.2 \%)$ demonstrated an intermediate level of stress and $152(51 \%)$ a high level. These categories were set in accordance with those previously developed for the PSS-10 by Juczyński and Ogińska-Bulik (2009).

Due to the large age diversity, the study group was divided into two subgroups divided by the mean age (32 years): a younger group (18-31 years) and an older group (32 and more). The results of the analysis indicate that age differentiates the intensity of perceived stress: the younger group $(\mathrm{M}=20.88$; $\mathrm{SD}=6.76)$ reported a higher level than the older group $(\mathrm{M}=18.49 ; \mathrm{SD}=6.76$; $\mathrm{t}=-2.94 ; \mathrm{p}<0.004)$.

The studied group tended to use varied coping strategies (Table 1). The mean values obtained do not differ significantly from those obtained in standardization tests (Juczyński \& Ogińska-Bulik, 2009).

The selection of coping strategies vary according to sex. The women were more likely to employ the following strategies: seeking emotional support $(\mathrm{t}=-2.30 ; \mathrm{p}<0.022)$, seeking instrumental support $(\mathrm{t}=-2.86 ; \mathrm{p}<0.005)$ and self-distraction $(\mathrm{t}=-3.01 ; \mathrm{p}<0.003)$. The men, however, were more likely to use acceptance $(\mathrm{t}=2.39 ; \mathrm{p}<0.017)$ and sense of humor $(\mathrm{t}=3.50 ; \mathrm{p}<0.001)$.

Also, age was found to determine the approach for dealing with difficult situations. The younger group members were more willing to seek emotional support ( $\mathrm{t}=-2.36 ; \mathrm{p}<0.019)$, seek instrumental support $(\mathrm{t}=-2.07 ; \mathrm{p}<0.04)$, or use venting $(\mathrm{t}=-4.92 ; \mathrm{p}<0.0001)$, substance use $(\mathrm{t}=-3.91 ; \mathrm{p}<0.0001)$, behavioral disengagement $(\mathrm{t}=-2.64 ; \mathrm{p}<0.009)$ and self-blaming $(\mathrm{t}=-3.50 ; \mathrm{p}<0.001)$; in contrast, the older group was more likely to use positive reframing $(t=3.27$, $\mathrm{p}<0.001)$ and turning to religion $(\mathrm{t}=2.73 ; \mathrm{p}<0.007)$.

Individuals with a higher level of stress appeared to be more likely to use avoidance coping strategies, such as venting $(\mathrm{F}=1.64 ; \mathrm{p}<0.02)$, substance use $(\mathrm{F}=1.60 ; \mathrm{p}<0.03 ;)$, behavioral disengagement $(\mathrm{F}=3.31 ; \mathrm{p}<0.000)$, self-blame $(\mathrm{F}=2.26 ; \mathrm{p}<0.000)$. In contrast, people experiencing a lower level of stress tended to use active strategies, such as positive reframing $(\mathrm{F}=2.15, \mathrm{p}<0.000)$, acceptance $(\mathrm{F}=2.11, \mathrm{p}<0.001)$ and sense of humor $(\mathrm{F}=1.98 ; \mathrm{p}>0.002)$.

A correlation analysis was performed to examine the relationship between coping strategies and the level of stress. The results (Table 2) indicate a positive relationship between the level of stress and use of non-adaptive strategies (self-blame, behavioral disengagement, substance use, venting and denial) and a negative relationship between the level of stress and the use of more active, 
adaptive strategies (active coping, positive reframing or planning, acceptance and sense of humor).

Table 2. Correlation coefficients of level of stress and coping strategies

\begin{tabular}{|l|c|}
\hline Brief Cope & PSS-10 \\
\hline Active coping & $-0.22^{* *}$ \\
\hline Planning & $-0.22^{* *}$ \\
\hline Positive reframing & $-0.32^{* *}$ \\
\hline Acceptance & $-0.27^{* *}$ \\
\hline Sense of humour & $-0.16^{* *}$ \\
\hline Turning to religion & 0.05 \\
\hline Seeking of emotional support & -0.04 \\
\hline Seeking of instrumental support & 0.09 \\
\hline Self-distraction & 0.11 \\
\hline Denial & $0.16^{* *}$ \\
\hline Venting & $0.23^{* *}$ \\
\hline Substance use & $0.24^{* *}$ \\
\hline Behavioural disengagement & $0.39^{* *}$ \\
\hline Self-blame & $0.42^{* *}$ \\
\hline
\end{tabular}

Note: ${ }^{* *} \mathrm{p}<.001$

Source: Authors' research.

Finally, hierarchical and stepwise regression was used to identify which of the independent variables (gender, age, coping strategies) allow for prediction of the level of perceived stress (Tables 3-4). The results indicate that age and gender are weak predictors of the level of perceived stress, explaining only about $10 \%$ of the variance of the dependent variable. Adding coping strategies at the last step significantly improved the model, explaining $38.5 \%$ of the dependent variable variance. The coping strategies are definitely better predictors of perceived stress level than the abovementioned demographic variables.

Stepwise regression was then performed to determine the predictive role of individual coping strategies, with all coping strategies being entered in the model as variables. Altogether, the coping strategies were found to explain $31 \%$ of the variance of perceived stress. Out of these, self-blame, behavioral disengagement, venting and substance use were found to increase the level of experienced stress, as indicated by the positive Beta coefficients in the prediction, and hence can be considered ineffective. In contrast, positive reframing and 
Magdalena Zadworna, Paulina Michalska, Magdalena Kobylarczyk Stress and Coping...

acceptance were found to have negative Beta coefficients, and hence to be predictors of low stress levels; these strategies can help the individual to cope with stress.

Table 3. Summary of the hierarchical regression analysis for variables predicting perceived stress level

\begin{tabular}{|c|c|c|c|c|c|c|}
\hline \multicolumn{2}{|r|}{ Model } & B & SE & Beta & $\mathrm{t}$ & $p$ \\
\hline 1 & Sex & 3.563 & .808 & .249 & 4.407 & .000 \\
\hline \multirow{2}{*}{2} & Sex & 3.855 & .798 & .270 & 4.829 & .000 \\
\hline & Age & -.095 & .027 & -.193 & -3.458 & .001 \\
\hline \multirow{16}{*}{3} & Sex & 2.736 & .729 & .191 & 3.755 & .000 \\
\hline & Age & -.038 & .026 & -.078 & -1.486 & .138 \\
\hline & Active coping & -.388 & .301 & -.075 & -1.290 & .198 \\
\hline & Planning & -.093 & .326 & -.018 & -.285 & .776 \\
\hline & Positive reframing & -.471 & .255 & -.107 & -1.847 & .066 \\
\hline & Acceptance & -.583 & .286 & -.114 & -2.040 & .042 \\
\hline & Sense of humour & -.243 & .239 & -.056 & -1.017 & .310 \\
\hline & Turning to religion & .196 & .182 & .055 & 1.076 & .283 \\
\hline & Seeking of emotional support & -.865 & .299 & -.212 & -2.898 & .004 \\
\hline & Seeking of instrumental support & .710 & .301 & .178 & 2.355 & .019 \\
\hline & Self-distraction & .092 & .248 & .020 & .372 & .710 \\
\hline & Denial & -.065 & .256 & -.013 & -.255 & .799 \\
\hline & Venting & .377 & .269 & .080 & 1.400 & .162 \\
\hline & Substance use & .558 & .225 & .126 & 2.478 & .014 \\
\hline & Behavioral disengagement & .791 & .274 & .163 & 2.887 & .004 \\
\hline & Self-blame & .830 & .218 & .212 & 3.811 & .000 \\
\hline
\end{tabular}

Step $1 \mathrm{R}^{2}=.062 ; \mathrm{F}=19.42 ; \mathrm{p}<.001$

Step $2 R^{2}=.099 ; F=16.05 ; p<.001 ; \Delta R^{2}=.037$

Step $3 R^{2}=.385 ; F=10.87 ; p<.001 ; \Delta R^{2}=.291$

Source: Authors' research. 
Table 4. Summary of the stepwise regression analysis for coping strategies predicting perceived stress level

\begin{tabular}{|l|c|c|c|c|c|}
\hline & $\mathrm{B}$ & $\mathrm{SE}$ & Beta & $\mathrm{t}$ & $\mathrm{p}$ \\
\hline Self-blame & 1.644 & .207 & .420 & 7.943 & .000 \\
\hline Positive reframing & -1.097 & .227 & -.250 & -4.826 & .000 \\
\hline Behavioural disengagement & 1.015 & .271 & .209 & 3.742 & .000 \\
\hline Acceptance & -.717 & .275 & -.141 & -2.611 & .009 \\
\hline Venting & .596 & .248 & .126 & 2.408 & .017 \\
\hline Substance use & .472 & .228 & .106 & 2.075 & .039 \\
\hline $\mathrm{R}^{2}=.313 ; \mathrm{F}=21.95 ; \mathrm{p}<.001$ &
\end{tabular}

Source: Authors' research.

\section{Discussion}

The aim of the current study was to assess the level of perceived stress and coping strategies among attendees of a stress management intervention performed during the 2019 Science, Technology and Art Festival in Lodz, and to identify the relationship between variables in the studied group of participants.

Our study addressed four research questions. The first examined the level of stress of the participants and the coping strategies they employed. It was found that the group demonstrated a high mean perceived stress level. This result corresponds with other research based on volunteers, which indicated that interest in the subject of stress psychology workshops and stress management interventions may be associated with increased stress levels (Pierceall \& Keim, 2007). In addition, our participants were found to employ a range of coping strategies; however, the mean values obtained for the coping strategies did not differ significantly from those obtained in previous standardization tests (Juczyński \& Ogińska-Bulik, 2009): active coping strategies such as active coping, planning and positive reframing dominated, together with seeking support, acceptance and self- distraction. In contrast, substance use and denial were used least frequently.

Regarding the effect of age and gender on the severity of stress and choice of coping strategy, it was found that women perceived a higher level of stress than men. These findings are confirmed by previous studies, although no significant gender differences were observed in a previous paper describing the Polish adaptation of the PSS-10 (Juczyński \& Ogińska-Bulik, 2009). Barbosa-Leiker et al. (2013) found women to perceive greater stress than men, as measured by the Perceived Stress Scale. Similar results have been noted in the general adult 
population (Cohen \& Williamson, 1988) and groups of psychiatric patients (Martin et al, 1995), college students in the USA (Pierceall \& Keim, 2007), university students in Turkey (Örücü \& Demir, 2009) and cardiology patients (Xu et al., 2015). Not only can the two sexes be burdened by different stressors, but it appears that some stressors exert different effects according to sex. This seems to be consistent with traditional roles and expectations. Moreover, changes in social context, such as increased labor force participation among women, as well as higher rates of divorce and single parenthood, significantly influence the social roles of women in the younger generation, and can become important stressors (Williams \& Kurina, 2002).

Our findings indicate that the female participants were more likely to seek emotional and instrumental support and use self-distraction as coping strategies, while men were more willing to use acceptance and sense of humor. Such differences in coping strategy have been discussed by a number of other authors (Mataud, 2004; Kelly at al., 2008; Meléndez at al., 2012). It has been proposed that women prefer emotional and avoidant coping styles; this is consistent with the socialization hypothesis, which predicts that women are taught to utilize more passive, emotion-focused behaviors. Women are believed to experience more stressful events related to health and family, while men are more stressed by events related to their work and finances. Patton and Goddard (2006) found the use of a particular type of strategy to be associated with the level of perceived stress, with certain types of activities being more or less stressful than others. Hence, stress management interventions should recognize and address different sources of stress for men and women.

Our findings indicate that age influences the level of perceived stress and the likelihood of reaching for certain ways of dealing with difficult situations, with younger participants tending to report higher stress levels than older ones. Although this finding is inconsistent with the Polish sample used in the Polish language adaptation of the Brief Cope study (Juczyński \& Ogińska-Bulik, 2009), similar results have been obtained in previous studies (Klein et al., 2016). Such age-based differences in stress level may reflect the different types of stressors encountered in everyday life by community-dwelling adults. For example, Chen, Peng, Xu and O'Brien (2018) report that young adults were most likely to report school-related stressors and middle-aged adults work-related stressors, and that the older adults were more likely than young and middle-aged adults to report health-related stressors.

In our study, the younger participants were also more willing to choose seeking emotional support, venting, substance use, behavioral disengagement 
and self-blame as strategies, while the older respondents tended to rely on positive reframing and turning to religion. Similarly, in the Polish Brief Cope adaptation, younger groups tended to give higher mean scores for coping strategies (Juczyński \& Ogińska-Bulik, 2009). A significant decline of problem-solving coping has been noted in old age (Meléndez at al., 2012). Aging is typically connected with experiencing fewer important life events and following more of a routine. Furthermore, many of the situations elderly subjects face are characterized by an element of loss with regard to specific developmental tasks: health deterioration, retirement and the passing of loved ones (Zadworna-Cieślak \& Ogińska-Bulik, 2019). Hence, it is expected that positive reframing and turning to religion would become predominant strategies in the period of late adulthood, as it is difficult to apply problem-solving actions to cope with such stressors. Age-related changes may preclude the use of some strategies and be associated with a decline in the use of others (LaChapelle \& Hadjistavropoulos, 2005; Osmanovic-Thunström et al., 2015).

The third research question explored the relationship between the level of perceived stress and the choice of coping strategy. The correlation analyses revealed positive relationships between the level of perceived stress and the use of strategies such as self-blame, behavioral disengagement, substance use, venting and denial; they also found a negative relationship between the stress level and the use of active coping, positive reframing, planning, acceptance and sense of humor. Similar result have been obtained in previous studies (Koopman at al., 2000; Halama \& Bakosova, 2009; Al-Sowygh, 2013; Garcia et al., 2018).

Coping strategies may be classified as adaptive or maladaptive depending on various factors. Meyer (2001) classified venting, denial, substance use, behavioral disengagement, self-distraction and self-blame, measured by BriefCope, as maladaptive coping. While such strategies are related to mental health problems, adaptive coping strategies such as positive reframing, planning and seeking social support, active coping, use of emotional and instrumental support, acceptance, religion and humor, are related to psychological well-being.

The final research question concerned the predictors of perceived stress. Regression analysis indicated that while age and gender are weak predictors of the level of perceived stress, coping strategies play a much greater role. Among these, self-blame (positive) and positive reframing (negative) were found to have the highest predictive impact on the stress level. In addition, behavioral disengagement, venting and substance use also increased the level of experienced stress, and can hence be considered ineffective. Similar results have been obtained in previous studies (Doron et al., 2014), with self-blame having 
a particularly strong effect on the stress level: this being a strategy that implies a sense of responsibility for negative results, internalizing the attribution towards the stressful event and affecting the level of personal distress (Ullman at al., 2014). In contrast, positive reframing and acceptance were found to play a protective role against perceived stress, and can be conceived as adaptive coping, as noted previously (Meyer, 2001; Urcuyo at al., 2005; Yi-Frazier et al., 2010; Al-Sowygh, 2013). Nevertheless, it is important to note that the effectiveness of a strategy is dependent on context of the situation; therefore, even a maladaptive strategy may be beneficial in dealing with some specific situations, such as experienced trauma (Ogińska-Bulik \& Zadworna-Cieślak, 2018).

Stress management is an important element of promoting psychological well-being and mental health (Gigantesco et al., 2019). However, the general population employs an understanding of stress gathered from a range of sources, most of which are not professional ones, and most information on the subject is not based on reliable scientific evidence. Our present findings also indicate areas for improvement in the annual interventions program taking place during The Science Festival in Lodz.

Our findings indicate that level of perceived stress and use of coping strategies differ according to sex and age. Therefore, stress management interventions should take these factors into account, as well as the stressors specific to different developmental periods (Meléndez at al., 2012). Moreover, negative relationships were identified between the stress level and the use of active coping, planning, positive reframing, acceptance and sense of humor as coping strategies; therefore, increasing the range of coping strategies employed by a patient and strengthening their adaptive ways of coping may be another important element of any intervention.

Denial, venting, substance use, behavioral disengagement and self-blame were found to be positively correlated with perceived stress. Out of these, self-blame turned out to be a particularly strong predictor of perceived stress. Therefore, stress management interventions may therefore be improved by discussing the potential effects of non-adaptive strategies and their relationship to deterioration of psychosocial functioning, the harmful effects of self-blame in particular; future studies should also examine the effectiveness of interventions for well-being (Kim et al., 2010).

Learning about stress and expanding the repertoire of strategies used to cope with it seems to contribute positively to mental health. Although a wide variety of intervention formats exists, research confirms that psychoeducation is particularly effective at reducing stress and enhancing wellbeing (Gutowska- 
Wyka at al., 2011; Van Daele et al., 2012; Zadworna-Cieślak, 2015). Those outcomes can be obtained in a wide range of subjects. Even a one-time intervention can be beneficial (Burkhart at al., 2018). The Science, Technology and Art Festival in Poland is therefore an important way to support such communitybased psychoeducation.

The study does have some limitations. The study group was mostly female. The impact of other important factors that may have influenced the level of dependent variable was not analyzed, the study was a cross-sectional one, which does not allow cause-effect relationships to be predicted between variables, and stress levels and coping strategies were measured through self-description, which may involve the impact of social approval on the results. Moreover, the sample was non randomly selected which limits the range of conclusions. The participants volunteered to gain some knowledge about their own psychological functioning relating to stress; it is possible that such people have a higher level of insight or, due to the purpose of the intervention, experience more stress than those from the general population. Nevertheless, despite its limitations, its findings increase awareness of stress and coping, and can be used to improve stress management interventions. The findings will be used to improve interventions directed to this group, including the first measurements. Further research should be focused on improving the effectiveness of such interventions.

\section{References}

Al-Sowygh, Z. H. (2013). Academic Distress, Perceived Stress and Coping Strategies among Dental Students in Saudi Arabia. The Saudi Dental Journal, 25(3), 97-105, doi: 10.1016/j.sdentj.2013.05.002.

Barbosa-Leiker, C., Kostick, M., Lei, M., McPherson, S., Roper, V., Hoekstra, T., \& Wright, B. (2013). Measurement Invariance of the Perceived Stress Scale and Latent Mean Differences across Gender and Time. Stress and Health, 29(3), 253-260, doi: 10.1002/ smi.2463.

Billings, A. G., \& Moos, R. H. (1981). The Role of Coping Responses and Social Resources in Attenuating the Stress of Life Events. Journal of Behavioral Medicine, 4(2), 139-157, doi: 10.1007/BF00844267.

Burkhart, K., Mason, E., \& Lazebnik, R. (2018). Stress Management Intervention: A Pilot Evaluation in an Urban Adolescent Medicine Clinic. Clinical Pediatrics, 57(6), 700-705, doi: 10.1177/0009922817733704.

Carver, C. S. (1997). You Want to Measure Coping but your Protocol's too Long: Consi- 
Magdalena Zadworna, Paulina Michalska, Magdalena Kobylarczyk Stress and Coping...

der the Brief COPE. International Journal of Behavioral Medicine, 4(1), 92-100, doi: 10.1207/s15327558ijbm0401_6.

Chen, Y., Peng, Y., Xu, H., \& O’Brien, W. H. (2018). Age Differences in Stress and Coping: Problem-Focused Strategies Mediate the Relationship between Age and Positive Affect. The International Journal of Aging and Human Development, 86(4), 347-363, doi: $10.1037 / \mathrm{a} 0021285$.

Cohen, S., \& Williamson, G. M. (1988). Perceived Stress in a Probability Sample in the United States. In: S. Spacapan, \& S. Oskamp (Eds.), The Social Psychology of Health (pp. 31-67). Newbury Park, CA: Sage.

Crum, A. J., Jamieson, J. P., \& Akinola, M. (2020). Optimizing Stress: An Integrated Intervention for Regulating Stress Responses. Emotion, 20(1), 120-125, doi: 10.1037/ a0025719.

Crum, A. J., Salovey, P., \& Achor, S. (2013). Rethinking Stress: The Role of Mindsets in Determining the Stress Response. Journal of Personality and Social Psychology, 104(4), 716-733, doi: 10.1037/a0031201.

Doron, J., Trouillet, R., Gana, K., Boiché, J., Neveu, D., \& Ninot, G. (2014). Examination of the Hierarchical Structure of the Brief COPE in a French Sample: Empirical and Theoretical Convergences. Journal of Personality Assessment, 96(5), 567-575, doi: 10.1080/00223891.2014.886255.

Folkman, S., \& Lazarus, R. S. (1980). An Analysis of Coping in a Middle-Aged Community Sample. Journal of Health and Social Behavior, 21(3), 219-239, doi: 10.2307/2136617.

García, F. E., Barraza-Peña, C. G., Wlodarczyk, A., Alvear-Carrasco, M., \& Reyes-Reyes, A. (2018). Psychometric Properties of the Brief-COPE for the Evaluation of Coping Strategies in the Chilean Population. Psicologia: Reflexão e Crítica, 31(1), 22, doi: 10.1186/s41155-018-0102-3.

Gigantesco, A., Palumbo, G., Zadworna-Cieślak, M., Cascavilla, I., Del Re, D., \& Kossakowska, K., WST European Group. (2019). An International Study of Middle School Students' Preferences about Digital Interactive Education Activities for Promoting Psychological Well-Being and Mental Health. Annali dell' Istituto Superiore di Sanita, 55(2), 108-117, doi: 10.4415/ANN_19_02_02.

Gutowska-Wyka, A., Kaflik-Pieróg, M., \& Zadworna-Cieślak, M. (2011). Stres i radzenie sobie ze stresem w okresie ciąży u nieletnich dziewcząt i kobiet [Stress and Dealing with Stress during Pregnancy in Underage Girls and Women]. In: E. Bielawska-Batorowicz, \& L. Golińska (Eds.), Rodzina i praca w warunkach kryzysu [Family and Work in Crisis], (pp. 553-562). Łódź: Wydawnictwo UŁ.

Halama, P., \& Bakosova, K. (2009). Meaning in Life as a Moderator of the Relationship between Perceived Stress and Coping. Studia Psychologica, 51(2/3), 143-148. 
Juczyński, Z., \& Ogińska-Bulik, N. (2009). Narzędzia pomiaru stresu i radzenia sobie ze stresem [Stress Measuring and Stress Management Tools]. Warszawa: Pracownia Testów Psychologicznych Polskiego Towarzystw Psychologicznego.

Kelly, M. M., Tyrka, A. R., Price, L. H., \& Carpenter, L. L. (2008). Sex Differences in the Use of Coping Strategies: Predictors of Anxiety and Depressive Symptoms. Depression and Anxiety, 25(10), 839-846, doi: 10.1002/da.20341.

Kim, J., Yeob Han, J., Shaw, B., McTavish, F., \& Gustafson, D. (2010). The Roles of Social Support and Coping Strategies in Predicting Breast Cancer Patients' Emotional Well-being: Testing Mediation and Moderation Models. Journal of Health Psychology, 15(4), 543-552, doi: 10.1177/1359105309355338.

Klein, E. M., Brähler, E., Dreier, M., Reinecke, L., Müller, K. W., Schmutzer, G., \& Beutel, M. E. (2016). The German Version of the Perceived Stress Scale-Psychometric Characteristics in a Representative German Community Sample. BMC Psychiatry, 16(1), 159, doi: 10.1186/s12888-016-0875-9.

Koopman, C., Gore-Felton, C., Marouf, F., Butler, L. D., Field, N., Gill, M., \& Spiegel, D. (2000). Relationships of Perceived Stress to Coping, Attachment and Social Support among HIV-positive Persons. Aids Care, 12(5), 663-672, doi: $10.1080 / 095401200750003833$.

LaChapelle, D. L., \& Hadjistavropoulos, T. (2005). Age-Related Differences Among Adults Coping with Pain: Evaluation of a Developmental Life-Context Model. Canadian Journal of Behavioural Science/Revue Canadienne des Sciences du Comportement, 37(2), 123-137, doi: 10.1037/h0087250.

Lazarus, R. S., \& Folkman, S. (1984). Stress, Appraisal, and Coping. New York: Springer.

Martin, R. A., Kazarian, S. S., \& Breiter, H. J. (1995). Perceived Stress, Life Events, Dysfunctional Attitudes, and Depression in Adolescent Psychiatric Inpatients. Journal of Psychopathology and Behavioral Assessment, 17, 81-95, doi: 10.1007/BF02229205.

Matud, M. P. (2004). Gender Differences in Stress and Coping Styles. Personality and Individual Differences, 37(7), 1401-1415, doi: 10.1016/j.paid.2004.01.010.

McLeroy, K. R., Norton, B. L., Kegler, M. C., Burdine, J. N., \& Sumaya, C. V. (2003). Community-Based Interventions. American Journal of Public Health, 93(4), 529-533, doi: 10.2105/ajph.93.4.529.

Meléndez, J. C., Mayordomo, T., Sancho, P., \& Tomás, J. M. (2012). Coping Strategies: Gender Differences and Development throughout Life Span. The Spanish Journal of Psychology, 15(3), 1089-1098, doi: 10.1037/0882-7974.5.1.58.

Meyer, B. (2001). Coping with Severe Mental Illness: Relations of the Brief COPE with Symptoms, Functioning, and Well-Being. Journal of Psychopathology and Behavioral Assessment, 23(4), 265-277, doi: 10.1023/A:1012731520781. 
Mughairbi, F. A., Abdulaziz Alnajjar, A., \& Hamid, A. (2019). Effects of Psychoeducation and Stress Coping Techniques on Posttraumatic Stress Disorder Symptoms. Psychological Reports, doi: 10.1177/0033294118825101.

Ogińska-Bulik, N., \& Zadworna-Cieślak, M. (2018). The Role of Resiliency and Coping Strategies in Occurrence of Positive Changes in Medical Rescue Workers. International Emergency Nursing, 39, 40-45, doi: 10.1016/j.ienj.2018.02.004.

Örücü, M. Ç., \& Demir, A. (2009). Psychometric Evaluation of Perceived Stress Scale for Turkish University Students. Stress and Health, 25, 103-109, doi: 10.1002/smi.1218.

Osmanovic-Thunström, A., Mossello, E., Åkerstedt, T., Fratiglioni, L., \& Wang, H. X. (2015). Do Levels of Perceived Stress Increase with Increasing Age after Age 65? A Population-Based Study. Age and ageing, 44(5), 828-834, doi: 10.1093/ageing/afv078.

Park, C. L., Armeli, S., \& Tennen, H. (2004). Appraisal-Coping Goodness of Fit: A Daily Internet Study. Personality and Social Psychology Bulletin, 30, 558-569, doi: $10.1177 / 0146167203262855$.

Patton, W. A., \& Goddard, R. (2006). Coping with Stress in the Australian Job Network: Gender Differences. Journal of Employment Counseling, 43, 135-144, doi: 10.1002/ j.2161-1920.2006.tb00013.x.

Pierceall, E. A., \& Keim, M. C. (2007). Stress and Coping Strategies among Community College Students. Community College Journal of Research and Practice, 31(9), 703-712, doi: 10.1080/10668920600866579.

Reynard, A. K., Sullivan, A. B., \& Rae-Grant, A. (2014). A Systematic Review of Stress-Management Interventions for Multiple Sclerosis Patients. International Journal of MS Care, 16(3), 140-144, doi: 10.7224/1537-2073.2013-034.

Roohafza, H., Sarrafzadegan, N., Sadeghi, M., Talaei, M., Talakar, M., \& Mahvash, M. (2012). The Effectiveness of Stress Management Intervention in a Community-Based Program: Isfahan Healthy Heart Program. ARYA Atherosclerosis, 7(4), 176.

Stowell, J. R., Kiecolt-Glaser, J. K., \& Glaser, R. (2001). Perceived Stress and Cellular Immunity: When Coping Counts. Journal of Behavioral Medicine, 24(4), 323-339, doi: 10.1023/A:1010630801589.

Ullman, S. E., Peter-Hagene, L. C., \& Relyea, M. (2014). Coping, Emotion Regulation, and Self-Blaming as Mediators of Sexual Abuse and Psychological Symptoms in Adult Sexual Assault. Journal of Child Sexual Abuse, 23(1), 74-93, doi: 10.1080/10538712.2014.864747.

Urcuyo, K. R., Boyers, A. E., Carver, C. S., \& Antoni, M. H. (2005). Finding Benefit in Breast Cancer: Relations with Personality, Coping, and Concurrent Well-Being. Psychology \& Health, 20(2), 175-192, doi: 10.1080/08870440512331317634. 
Van Daele, T., Hermans, D., Van Audenhove, C., \& Van den Bergh, O. (2012). Stress Reduction Through Psychoeducation: a Meta-Analytic Review. Health Education \& Behavior, 39(4), 474-485, doi: 10.1177/1090198111419202.

Williams, K., \& Kurina, L. M. (2002). The Social Structure, Stress, and Women's Health. Clinical Obstetrics and Gynecology, 45(4), 1099-1118, doi: 10.1097/00003081200212000-00018.

Xu, X., Bao, H., Strait, K., Spertus, J. A., Lichtman, J. H., D’Onofrio, G., \& Bueno, H. (2015). Sex Differences in Perceived Stress and Early Recovery in Young and Middle-Aged Patients with Acute Myocardial Infarction. Circulation, 131(7), 614-623, doi: 10.1161/CIRCULATIONAHA.114.012826.

Yi-Frazier, J. P., Smith, R. E., Vitaliano, P. P., Yi, J. C., Mai, S., Hillman, M., \& Weinger, K. (2010). A Person-Focused Analysis of Resilience Resources and Coping in Patients with Diabetes. Stress and Health, 26(1), 51-60, doi: 10.1002/smi.1258.

Zadworna-Cieślak, M. (2015). Dobrostan psychiczny seniorów - znaczenie oddziaływań psychoedukacyjnych [Mental Well-Being of Seniors - the Importance of Psychoeducational Effects]. In: V. Tanaś, \& W. Welskop (Eds.), Lifelong Learning (pp. 321-328). Łódź: Wydawnictwo Naukowe Wyższej Szkoły Biznesu i Nauk o Zdrowiu.

Zadworna-Cieślak, M., \& Ogińska-Bulik, N. (2019). Satisfaction with Life in Old Age - the Role of Developmental Tasks Attainment and Resiliency. Educational Studies Review, 28 (1), 23-35, doi: 10.12775/PBE.2019.002. 